\begin{tabular}{ll}
\hline Homepage: http:/jusami.batan.go.id & Jurnal Sains Materi Indonesia \\
\hline
\end{tabular}

\title{
STRUKTURMIKRO DAN SIFAT MAGNET PASIR BESI PASCA ULTRASONIFIKASI
}

\author{
S. Purwanto dan M. Dani \\ Pusat Sains dan Teknologi Bahan Maju (PSTBM) - BATAN \\ Kawasan Puspiptek, Serpong 15314, Tangerang Selatan \\ E-mail: setyo_p@batan.go.id
}

Diterima: 8 Juni 2017 Diperbaiki: 9 Oktober 2017 Disetujui: 13 Oktober 2017

\begin{abstract}
ABSTRAK
STRUKTURMIKRO DAN SIFAT MAGNET PASIR BESI PASCA ULTRASONIFIKASI. Struktur nano dan komposisinya yang berkaitan dengan sifat magnetik telah dipelajari dengan High Resolution Transmission Electron Microscope (HRTEM), Scanning Electron Microscopy Energy Dispersive Spectroscopy (SEM-EDS) dan Vibrating Sample Magnetometer (VSM) pada serbuk pasir besi sebelum dan sesudah ultrasonifikasi. Telah diketahui adanya dua fasa utama $\mathrm{Fe}_{3} \mathrm{O}_{4}$ dan $\mathrm{FeTiO}_{3}$ dengan fasa minor $\mathrm{Al}_{2} \mathrm{O}_{3}, \mathrm{MgO}$ dan $\mathrm{SiO}_{2}$ pada sampel tanpa perlakuan berdasarkan pengamatan dengan SEM-EDS. Sedangkan hasil pengamatan dengan HRTEM dapat dikonfirmasi adanya nanograin $\mathrm{Fe}_{3} \mathrm{O}_{4}$ dan $\mathrm{FeTiO}_{3}$ dengan diameter sekitar $10 \mathrm{~nm}$ pada serbuk pra-ultrasonik. Peningkatan nilai saturasi magnetik $\mathrm{Ms}=32,3 \mathrm{emu} / \mathrm{gram}, 34,5 \mathrm{emu} / \mathrm{gram}$ dan 46,4 emu/gr masing-masing untuk cuplikan pra-ultrasonik dan ulrasonifikasi selama 10 menit dan 30 menit, sedangkan medan koersif magnet $(\mathrm{Hc})$ dari 100,5 Oe menjadi 112,5 Oe.
\end{abstract}

Kata kunci: Pasir besi, Struktur mikro, Sifat magnetik, Ultrasonifikasi

\begin{abstract}
MICROSTRUCTURE AND MAGNETIC PROPETIES OF IRON SANDS POST ULTRASONIFICATION. The nanostructure and its composition related to the magnetic properties have been studied by High Resolution Transmission Electron Microscopy (HRTEM), Scanning Electron Microscopy Electron and Vibrating Sample Magnetometer (VSM) on pre and post ultrasonification iron sands powder. The two main phases of $\mathrm{Fe}_{3} \mathrm{O}_{4}$ and $\mathrm{FeTiO}$ have been found ${ }_{3}$ with a minor phase of $\mathrm{Al}_{2} \mathrm{O}_{3}, \mathrm{MgO}$ and $\mathrm{SiO}_{2}$ in pretreatment sample based on SEM-EDS measurement. From HRTEM results, the existence of nanograin of $\mathrm{Fe}_{3} \mathrm{O}_{4}$ and $\mathrm{FeTiO}_{3}$ in pre ultrasonic powder with diameter of around $10 \mathrm{~nm}$ was confirmed. Ultrasonification has improved the magnetic saturation properties from $M_{\mathrm{s}}=32.3 \mathrm{emu} / \mathrm{gr}$ to $34.5 \mathrm{emu} / \mathrm{gr}$ and $46.4 \mathrm{emu} / \mathrm{gr}$ for pre and post ultrasonification $10 \mathrm{~min}$ and $30 \mathrm{~min}$ respectively, with a slight change on coercive magnetic field (Hc) from 100.5 to 112.5 Oe.
\end{abstract}

Keywords: Iron sand, Microstructure, Magnetic properties, Ultrasonification

\section{PENDAHULUAN}

Pasir besi merupakan salah satu sumber kekayaan alam yang mempunyai banyak manfaat. Pasir besi mengandung banyak mineral yang dapat dimanfaatkan untuk berbagai kebutuhan. Telah diketahui bahwa pasir besi pantai selatan pulau Jawa khususnya Bantul dan Amdal banyak mengandung mineral magnetik yang terkandung seperti magnetite, hematite dan maghemite[1,2]. Sedangkan bergeser kearah Barat di sekitar pantai Cilacap endapan pasir besi lebih kaya akan mineral magnetite dan ilmenite [3].Mineral magnetik yang terkandung dalam pasir besi sangat bermanfaat, namun tidak semua mineral yang terkandung dimanfaatkan semua [4].

Pemanfaatan mineral pasir besi yang kini sedang dikembangkan ialah pasir besi berukuran nanopartikel [5]. Pasir besi dalam ukuran nano mempunyai banyak peluang aplikasi di bidang 
industri, elektronik dan medis [6], studi kemagnetan bumi $[7,8]$ dan pertahanan sebagai bahan anti radar [9].

Diketahui bahwa pasir besi dalam ukuran nano mempunyai sifat magnetik yang berbeda daripada pasir besi ukuran makro. Perlakuan ultrasonik pada sampel pasir besi (PB) dan karakterisasi dengan cara X-Ray Diffractometer (XRD), Scanning Electron Microscope (SEM), Vibrating Sample Magnetometer (VSM) dan High Resolution Transmission Electron Microscope (HRTEM) telah dilakukan. Studi kali ini menggunakan cuplikan pasir besi dari pantai Tasikmalaya, dengan tujuan untuk mengetahui pengaruh proses ultrasonifikasi yang terkait dengan komposisi dan sifat magnetik pada sampel pasir besi, serta untuk mengetahui medan koersif, Hc tidak berubah secara berarti walaupun telah dilakukan beberapa kali ulrasonikasi.

Hipotesanya adalah bahwa fasa-fasa magnetik pembentuk sifat magnet pasir besi terdistribusi merata sampai ukuran mikrometer bahkan nanometer. Sehingga perlu dilakukan pengamatan dengan teknik HRTEM untuk distribusi fasa tersebut.

\section{METODE PERCOBAAN}

\section{Bahan dan Alat}

Bahan yang digunakan adalah sampel pasir besi (pantai selatan Tasikmalaya). Peralatan karakterisasi yang digunakan adalah Scanning Electron Microscope (SEM) merek JEOL untuk analisis strukturmikro dan komposisi bahan, High Resolution Transmission Electron Microscope (HRTEM) merk FEI untuk analisis detil struktur nano dan d-spasing, Vibrating Sample Magnetometer (VSM) merek Oxford untuk analisis sifat magnet serbuk. Sedangkan proses ulrasonifikasi menggunakan alat ultrasonifikasi.

\section{Cara Kerja}

\section{Modifikasi Pasir Besi}

Dilakukan dengan proses ultrasonifikasi. Material sampel dicampurkan dengan aquadest $20 \mathrm{~mL}$, kemudian digetarkan dengan gelombang ultrasonik pada frekuensi tertentu dengan variasi waktu 10 menit dan 30 menit.

\section{Karakterisasi Sifat Bahan}

Karakterisasi dengan SEM-EDS, VSM dan HRTEM dilakukan pada bahan pasir besi yang belum dimodifikasi dan yang telah dimodifikasi. Khusus cuplikan untuk HRTEM dilakukan pada partikel pra ulrasonifikasi dengan ukuran partikel kurang dari 1 mikrometer.

\section{HASIL DAN PEMBAHASAN}

\section{Morfologi dan Kandungan Unsur Pasir Besi}

Dari citra foto Scanning Electron Microscope (SEM) pasir besi pada Gambar 1., diketahui bahwa pada ketiga sampel mempunyai ukuran butiran yang relatif sama antara $50 \mu \mathrm{m}$ hingga $300 \mu \mathrm{m}$. Artinya, bahwa penambahan waktu proses ultrasonik pada pasir besi belum mampu memperkecil ukuran butiran. Namun, terlihat bahwa penambahan waktu ultrasonik ini mampu
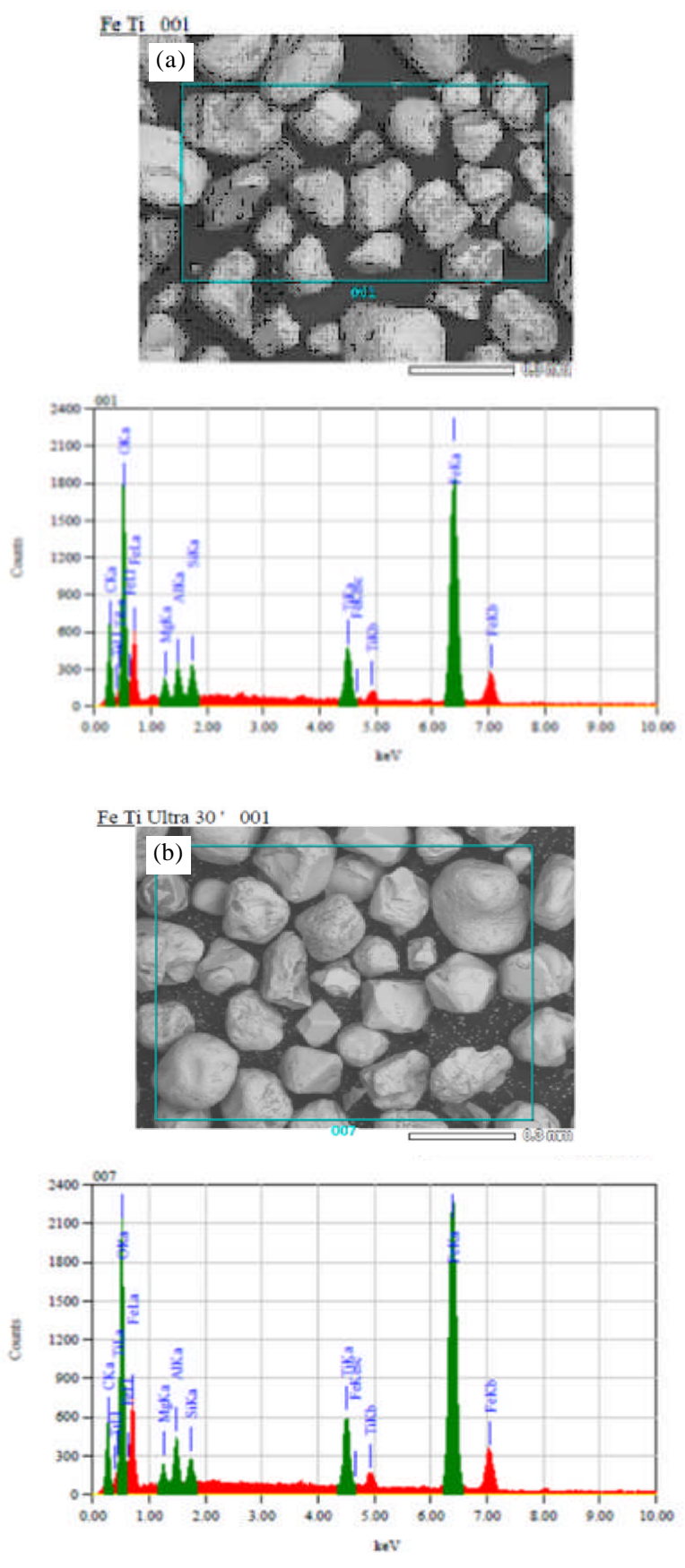

Gambar 1. Citra SEM dan spektrum EDS dari cuplikan Pasir besi (PB) (a). orisinil perbesaran 100x, (b). pasca ulrasonikasi 30 menit. 
Tabel 1. Nilai \% atom unsur pada pasir besi dengan SEM-EDS

\begin{tabular}{lcccccc}
\hline \multirow{2}{*}{ Sampel } & \multicolumn{7}{c}{$\%$ atom } \\
\cline { 2 - 7 } & $\mathrm{Fe}$ & $\mathrm{Ti}$ & $\mathrm{O}$ & $\mathrm{Si}$ & $\mathrm{Al}$ & $\mathrm{Mg}$ \\
\hline $\begin{array}{l}\text { Pasir besi tanpa } \\
\text { perlakuan }\end{array}$ & 16,4 & 2,2 & 45,2 & 1,2 & 1,6 & 1,2 \\
$\begin{array}{l}\text { Pasir Besi ultrasonik } \\
10 \text { menit }\end{array}$ & 17,0 & 2,3 & 46,7 & 1,8 & 1,9 & 1,5 \\
$\begin{array}{l}\text { Pasir Besi ultrasonik } \\
30 \text { menit }\end{array}$ & 19,9 & 2,7 & 46,9 & 0,9 & 2,0 & 1,4 \\
\hline
\end{tabular}

Ket.: sisa at\% unsur Carbon sebagai bahan coating pada saat pengamatan

mengurangi pengotor pada pasir besi.seperti unsur Al, Mg dan Si. Berdasarkan Tabel 1. terlihat bahwa unsur utama pasir besi adalah $\mathrm{Fe}$, Ti dan O. Ketiga unsur tersebut semakin meningkat jumlahnya seiring dengan lamanya waktu proses ultrasonik. Hal ini menandakan bahwa semakin lama waktu ultrasonik maka prosentase fasa utama $\mathrm{Fe}_{3} \mathrm{O}_{4}$ atau magnetite meningkat masingmasing menjadi $4 \mathrm{~mol} \mathrm{Fe}_{3} \mathrm{O}_{4}, 5 \mathrm{~mol} \mathrm{Fe}_{3} \mathrm{O}_{4}$ dan $6 \mathrm{~mol} \mathrm{Fe}_{3} \mathrm{O}_{4}$ dengan $2 \mathrm{~mol} \mathrm{FeTiO}_{3}$.

\section{Sifat Magnetik Cuplikan Pasir Besi}

Dari Gambar 2(a) hingga Gambar 2(c) diketahui bahwa nilai medan saturasi, Ms yang terbesar adalah
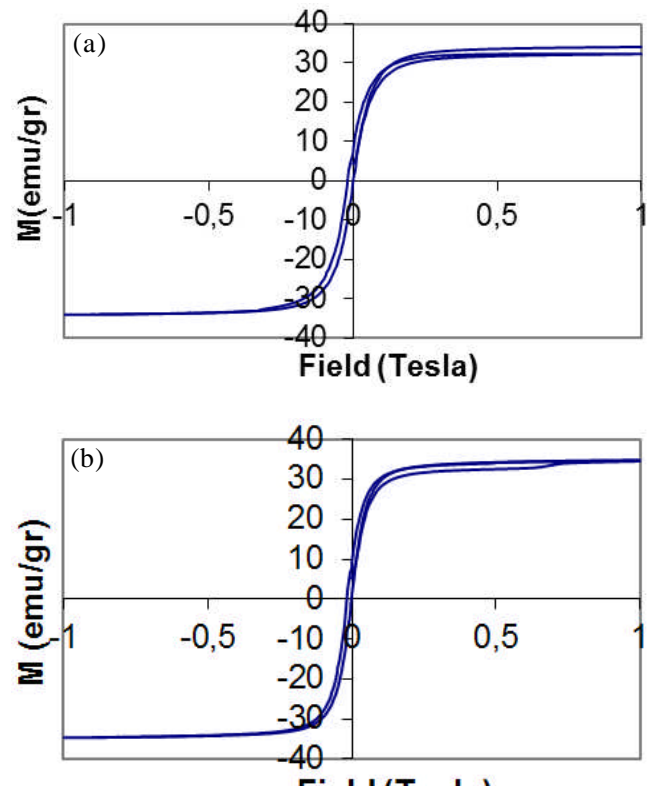

Field (Tesla)

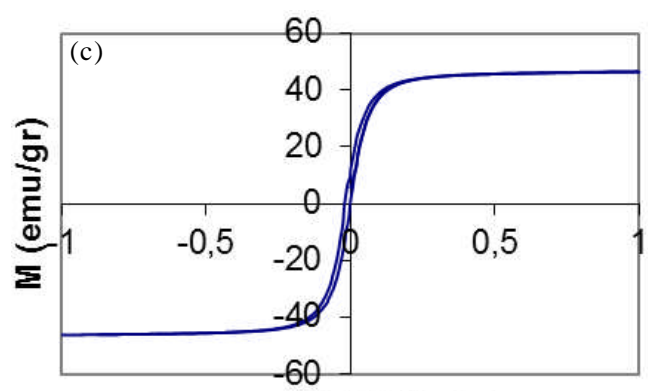

Field (Tesla)

Gambar 2. Kurva magnetisasi sampel pasir besi (a). Original, (b). 10 menit dan (c). 30 menit. pada sampel pasir besi yang telah di ultrasonik selama 30 menit yakni 46,4 emu/gram, dibanding dengan pasir besi yang tidak diultrasonikasi yakni 32,3 emu/gram. Nilai ini melampaui hasil pengukuran pasir besi BantulYogjakarta [1]. Nilai medan saturasi ini tidak hanya berhubungan dengan ukuran partikel magnetik namun berhubungan dengan banyaknya fasa pengotor pada sampel, dalam hal ini paduan $\mathrm{MgO}, \mathrm{SiO}_{2}$ dan $\mathrm{Al}_{2} \mathrm{O}_{3}$. Sifat fasa pengotor dapat mempengaruhi medan saturasi sampel sehingga semakin banyak fasa pengotor semakin kecil nilai medan saturasi sampel. Begitu pula dengan nilai medan magnetik remanence, $\mathrm{M}_{\mathrm{r}}$. Nilai magnetik remanence, $\mathrm{M}_{\mathrm{r}}$ dari cuplikan pasca ultrasonikasi cenderung meningkat dari 4,5 emu/gram, 5,2 emu/gram dan 10,0 emu/gram. Namun demikian nilai ini lebih baik dibanding dengan hasil pengukuran pada cuplikan pasir pantai Ambal yang hanya 5,5 emu/gr seperti dilaporkan oleh Bilalodin et.al,[2].

Fenomena ini dapat dipahami karena perlakuan ultrasonikasi selain faktor unsur pengotor berkurang, diduga juga karena fasa utama $\mathrm{FeFe}_{2} \mathrm{O}_{4}$ atau $\mathrm{Fe}_{3} \mathrm{O}_{4}$ menjadi dominan dibanding fasa ilminite [10]. Hal ini akan dikonfirmasi dengan mengamati struktur nano atau mikro pada cuplikan dengan teknik HRTEM. Disamping itu, menurut laporan penelitian Pauzan et al. [11], nilai $\mathrm{H}_{\mathrm{c}}$ mengalami penurunan seiring dengan semakin kecilnya ukuran butir. Nilai $\mathrm{H}_{\mathrm{c}}$ pada Tabel 2 di atas sedikit meningkat, hal ini menandakan bahwa ukuran partikel tidak berubah. Hasil ini relevan dengan data prosentase unsur berdasarkan uji $S E M-E D S$, yang menunjukkan bahwa ukuran butiran pasir besi tidak berubah.

Tabel 2. Parameter sifat kemagnetan tiap-tiap sampel.

\begin{tabular}{lcccc}
\hline \multicolumn{1}{c}{ Sampel } & $\begin{array}{c}\mathrm{Ms} \\
(\mathrm{emu} / \mathrm{gr})\end{array}$ & $\begin{array}{c}\mathrm{Hc} \\
(\mathrm{Oe})\end{array}$ & $\begin{array}{c}\mathrm{Mr} \\
(\mathrm{emu} / \mathrm{gr})\end{array}$ & $\begin{array}{c}\mathrm{X}\left(\mathrm{m}^{3} / \mathrm{kg}\right) \\
\mathrm{H}=1 \mathrm{Tesla}\end{array}$ \\
\hline $\begin{array}{l}\text { Pasir besi tanpa } \\
\text { perlakuan }\end{array}$ & 32,3 & 100,5 & 4,5 & $32,3 \times 10^{-6}$ \\
$\begin{array}{l}\text { Pasir Besi ultrasonik } \\
10 \text { menit }\end{array}$ & 34,5 & 100,5 & 5,2 & $34,5 \times 10^{-6}$ \\
$\begin{array}{l}\text { Pasir Besi ultrasonik } \\
30 \text { menit }\end{array}$ & 46,4 & 112,5 & 10 & $46,5 \times 10^{-6}$ \\
\hline
\end{tabular}

\section{Citra Morfologi Partikel Pasir Besi dengan teknik HRTEM}

Citra morfologi partikel cuplikan dengan HRTEM seperti Gambar 3, mempertegas eksistensi bahwa serbuk halus pasir besi bersifat multigrain dengan sebaran nanograin seukuran $10 \mathrm{~nm}$ dengan $d$-spasing [311] sebesar 2,525 ̊. Hasil ini sesuai dengan hasil pengamatan Toto et al.[1] dan Ghandoor et al. [12]. Sedangkan fasa ilminite $\mathrm{FeTiO}_{3}$ dijumpai dengan $d$ spasing 2,673 ^ yang mendekati nilai $d$-spasing bidang [112] untuk fasa tersebut, seperti dilaporkan oleh Hashishin, et al. dengan menganalisis pola Selected Area Electron Difraction (SAED) dari hasil citra TEM [13]. Tabel 3 menyajikan perbandingan $d$-spasing yang berhasil diamati dengan HRTEM pada cuplikan butiran 


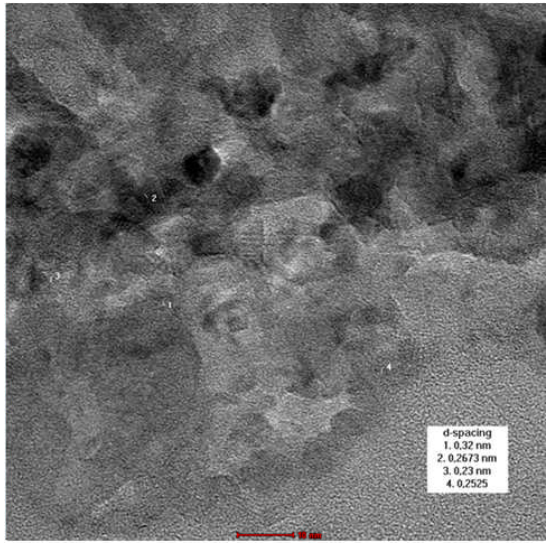

Gambar 3. Citra dari Selected Area Electron Diffraction $(S A E D)$ dari partikel pasir besi yang menunjukkan keberadaan pola difraksi oleh bidang (220) dan (311).

Tabel 3. $d$-spacing pengamatan cuplikan partikel pasir besi dengan HR-TEM.

\begin{tabular}{cccccc}
\hline $\begin{array}{c}\mathrm{d}(\AA) \\
\text { Cuplikan }\end{array}$ & $\begin{array}{c}\mathrm{d}(\AA) \\
\mathrm{Fe}_{3} \mathrm{O}_{4} \text { Ref. }\end{array}$ & $\begin{array}{c}\text { Bidang } \\
(\mathrm{hkl})\end{array}$ & $\begin{array}{c}\mathrm{d}(\AA) \\
\mathrm{FeTiO}_{3} \text { Ref. }\end{array}$ & $\begin{array}{c}\text { Bidang } \\
(\mathrm{hkl})\end{array}$ & $\begin{array}{c}\text { Nomor } \\
\text { Lokasi }\end{array}$ \\
\hline 3,200 & 2,970 & $(220)$ & & & 1 \\
2,673 & - & - & 2,562 & $(112)$ & 2 \\
2,525 & 2,530 & $(311)$ & & & 4 \\
2,300 & - & & 2,296 & $(422)$ & 3 \\
\hline
\end{tabular}

pasir besi orisinil dibandingkan dengan $d$-spasing referensi. Sedangkan Gambar 4 adalah citra SAED dari butiran pasir besi orisinil dimana terlihat jelas keberadaan bidang difraksi (311) dan (220) yang muncul dari fasa utama.

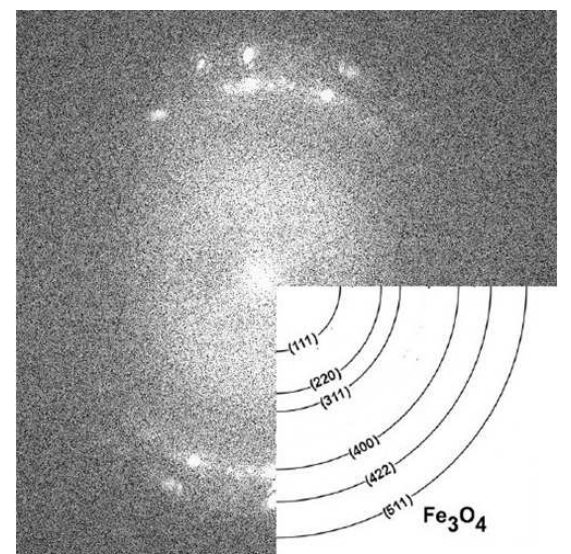

Gambar 4. Citra dari Selected Area Electron Diffraction $(S A E D)$ dari partikel pasir besi yang menunjukkan keberadaan pola difraksi oleh bidang (220) dan (311).

\section{KESIMPULAN}

Berdasarkan data SEM-EDS diperoleh infomasi kandungan unsur pada pasir besi yang paling dominan adalah $\mathrm{Fe}$, Ti dan $\mathrm{O}$. Hasil pengamatan struktur mikro $S E M-E D S$ yang diperkuat sampai skala nanometer dengan HR-TEM dari partikel pasir besi diketahui adanya fasa $\mathrm{Fe}_{3} \mathrm{O}_{4}$ dan $\mathrm{FeTiO}_{3}$. Keberadaan kedua fasa tersebut terdistribusi secara merata, seperti hasil citra HR-TEM. Pengukuran sifat magnet dengan VSM memperlihatkan bahwa nilai medan saturasi, $\mathrm{M}_{\mathrm{s}}$, nilai medan remanence, Mr maupun medan koersif, Hc mengalami peningkatan akibat proses ultrasonikasi. Peningkatan sifat magnet dari pasir besi khususnya nilai Ms, terjadi karena berkurangnya fasa pengotor seperti $\mathrm{SiO}_{2}$ akibat proses ultrasonifikasi. Proses ulrasonikasi yang lebih lama berpotensi untuk menghasilkan sifat magnet pasir besi yang lebih baik akibat berkurangnya fasa pengotor dari unsur $\mathrm{Al}_{2} \mathrm{O}_{3}$ dan $\mathrm{MgO}$.

\section{UCAPAN TERIMAKASIH}

Penulis mengucapkan banyak terimakasih kepada Kepala PSTBM dan BSBM atas ijin pelaksanaan penelitian. Riset ini merupakan bagian dari DIPA 2014. Penulis tidak lupa mengucapkan terimakasih kepada Drs. Bambang Sugeng, Dra. Deswita, Dra. Mujamilah, M.Sc, Fadli Rochman M.Si, Dr. Enni Sugiarti atas bantuan dan fasilitasinya.

\section{DAFTAR ACUAN}

[1]. Toto, R., Wildan M. W., Abraha K., Kusmono. "The Potential of Iron Sand from The Coast South of Bantul Yoyakarta as Raw Ceramic Magnet Materials." Jurnal Teknologi , vol. 5, no. 1, pp. 62-69, 2012.

[2]. Bilalodin, Sunardi, Effendy M. "Analisis Kandungan Senyawa Kimia dan Uji Sifat Magnetik Pasir Besi Pantai Amdal.” Jurnal Fisika Indonesia vol. XVII, no. 50, pp. 29-31, 2013.

[3]. Kurnio H. "Review of Coastal Characteristics of Iron Sand Deposits in Cilacap Cenral Java." Bulletin of the Marine Geology, vol. 22, no. 1, pp. 35-50, 2007.

[4]. Sunaryo, \& Sugihartono, I. "Pemisahan Senyawa Titanomagnetite dari Pasir Alam Indramayu, Jawa Barat." Makara Teknologi, vol. 14, no. 2, pp. 106-110, 2010.

[5]. Sunaryono, Taufiq, A., Nurdin dan Darminto. "Kontribusi Filler Magnetik $\mathrm{Fe}_{3} \mathrm{O}_{4}$ pada Efek Histerisis Magneto-Elastisitas Komposit Ferogel." Jurnal Fisika dan Aplikasinya, vol. 9, no. 1, pp. 37-41, 2013.

[6]. Teja A.S., Koh P.Y. "Synthesis , Properties, and Applications of Magnetic Iron Oxide Nanoparticles." Progress in Crystal Growth and Char. Mat., vol.55, pp. 22-45, 2009.

[7]. Kasama T., Church N.S., Feinberg J.M., Dunin Borkowski R.E., Harrison R.J. "Direct Observation of Ferromagnetic/Ferroelastic Domain Interactions in Magnetite Below The Verwey Transition." Earth and Planetary Science Letters, vol. 297, pp. 10-17, 2010. 
[8]. Kasama T., Harrison R.J., Church N.S., Na-gao M., Feinberg J.M. Dunin-Borkowski R.E. "Ferrimagnetic/Ferroelastic Domain Interactions in Magnetite Below Verwey Transition. Part I: Electron Holography and Lorentz Microscopy." Phase Transitions, vol. 86, no. 1, pp. 67-87, 2013.

[9]. Mashuri, Darminto, Triwikantoro, and W. Lestari. "Preparation and Microwave Absorbing Properties In X-band of Natural Ferrite from Iron Sands by High Energy Milling." Mater.Res. Express, at https://doi.org/10.1088/2053-1591/aa68b4, 2013.

[10]. Drummond, A.L., Feitoza, N.C., Duarte, G.C., Sales, J.K., Silva, L.P., Chaker, J.A., Bakuzis, A.F., and Sousa, M.H. "Reducing Size Dispersion in One Pot Aqueous Synthesis to Maghemite Nanoparticles." Journal of Nanoscience and Nanotechnology, vol. 12, no. 10, pp. 1-6, 2012.
[11]. Pauzan, M., Kato, T., Iwata, S. dan Suharyadi, E. "Pengaruh Ukuran Butir dan Struktur Kristal terhadap Sifat Kemagnetan pada Nanopartikel Magnetit $\left(\mathrm{Fe}_{3} \mathrm{O}_{4}\right)$." In Prosiding Pertemuan Ilmiah XXVII HFI, pp. 24-28, 2013.

[12]. H.El Ghandoor, H. M. Zidan, Mostafa M.H. Khalil and M. I. M. Ismail. "Synthesis and Some Physical Properties of Magnetite $\left(\mathrm{Fe}_{3} \mathrm{O}_{4}\right)$ Nanoparticles." Int. J. Electrochem. Sci., vol. 7, pp. 5734-5745, 2012.

[13]. Hashishin, T., Tan, Z., Yamamoto, K., Qiu, N., Kim, J., Numako, C., Naka T., Valmalette, J.C., Ohara, S. "Quenching Il-minite with a High-Temperature and Hih-Pressure Phase Using Super-High-Enegy Ball Milling." Sientific Reports4: 4700. DOI: 10.1038/ srep 04700, 2014. 